This is a postprint version of the following published document:

González, M., Kindelán, M., Cabanelas, J. C. \& Baselga, J. (2003). Modelling auto-acceleration in DGEBA/diamine systems. Macromolecular Symposia. Functional Networks and Gels, 200 (1), pp. 111-120.

DOI: $10.1002 / 10.1002 /$ masy.200351011

(C) Wiley, 2003 


\title{
Modelling Auto-Acceleration in DGEBA/Diamine Systems
}

\author{
M. González, M. Kindelán, J.C. Cabanelas, J. Baselga*
}

Instituto Tecnológico de Química y Materiales Álvaro Alonso Barba. Universidad Carlos III de Madrid. A v. Universidad 30, 28911 Leganés, M Tadrid, Spain

E-mail: jbaselga@ing.uc3m.es

\section{Summary:}

Curing of epoxy resins with aliphatie diamines at low temperatures deviates from the 4EQ meehanism (eatalytie and non-eatalytie dual path) at relatively low eonversions $r$ far from vitrifieation. Although the Horie meehanism relies on a third order reaetion it is possible a more realistie approaeh to epoxy euring kineties if a detailed analysis of auto-aeeeleration is made. A single parameter dependent only on the nature of the amine is proposed.

\author{
Keywords: \\ Amine \\ Auto-acceleration \\ Diamine systems \\ Epoxy-amine kinetics \\ Epoxy resin
}

\section{Introduction}

The mechanism of cure of an epoxy-amine system can be described by an equation where two paths of reaction are considered: uncatalyzed and catalyzed (auto-catalyzed) by the hydroxyl groups generated during the course of reaction. This mechanism was initially proposed by

Horie and coworkers ${ }^{[1]}$ and is in general widely accepted if no secondary reactions are present. Kamal and Dutta simplified this model assuming equal reactiv ity for the primary and secondary

amine addition reactions and generalising to an unknown reaction order. The proposed equation has been largely used for fitting purposes in many epoxy systems ${ }^{[4-7]}$ and gives good

agreements betw een theoretical predictions and experimental data in the early stages of the curing process, but giving place sometimes to unrealistic reaction orders, especially if the model is applied to the whole curing process up to vitrification. Recently, Paz-Abuín et al ${ }^{[8]}$ developed a new method to determine experimentally the reactivity ratio between secondary

and primary amine elemental rate constants. They found that the application of a mechanistic model to the curing of epoxy resıns with diamines at low temperatures deviates from

experimental conversion at relativelv low conversıons, far from gelation. ${ }^{[9]}$ The auto-acceleration was explained in terms of reduction of the available volume for the remaining reactive groups during the curing process. In this work, we have studied the kinetics of DGEBA reacting with different aliphatic diamines. The elemental rate constants were evaluated 
simultaneously from the differential rate equations for the reactions of epoxy and primary amine. A more realistic approach to epoxy curing kinetics is possible if a detailed analysis of auto-acceleration is made. Our proposal is to use a single parameter not dependent on curing conditions, just dependent on the nature of the species initially present.

\section{Theoretical Considerations}

The reaction of epoxy resins with aliphatic amines can be interpreted in terms of a fourequation (4EQ) kinetics mechanism which assumes that cure progresses through a noncatalysed path $\left(\mathrm{k}_{1}^{\prime}\right.$ and $\left.\mathrm{k}_{2}^{\prime}\right)$ and an auto-catalysed path $\left(\mathrm{k}_{1}\right.$ and $\left.\mathrm{k}_{2}\right)$. The subscript 1 or 2 indicates the reaction of epoxy groups with primary or secondary amine functionalities respectively:

$$
\begin{aligned}
& \mathrm{A}_{1}+\mathrm{E} \stackrel{\mathrm{k}_{1}^{\prime}}{\longrightarrow} \mathrm{A}_{2}+\mathrm{OH}^{-} \\
& \mathrm{A}_{2}+\mathrm{E} \stackrel{\mathrm{k}_{2}^{\prime}}{\longrightarrow} \mathrm{A}_{3}+\mathrm{OH}^{-} \\
& \mathrm{A}_{1}+\mathrm{E} \stackrel{\mathrm{k}_{1}, \mathrm{OH}^{-}}{\longrightarrow} \mathrm{A}_{2}+\mathrm{OH}^{-} \\
& \mathrm{A}_{2}+\mathrm{E} \stackrel{\mathrm{k}_{2}, \mathrm{OH}^{-}}{\longrightarrow} \mathrm{A}_{3}+\mathrm{OH}
\end{aligned}
$$

Four rate equations can be established for the variation in epoxy, primary amine, secondary amine and tertiary amine groups. If we take into account the mass balances then, after some algebraic manipulation, equations can be rearranged in two related differential equations, expressed in terms of epoxy $(\alpha)$ and primary amine $(\beta)$ conversions:

$$
\begin{aligned}
& \alpha=\frac{E_{0}-E}{E_{0}} \quad \beta=\frac{A_{10}-A_{1}}{A_{10}} \quad B=\frac{2 A_{10}}{E_{0}} \\
& \frac{d \alpha}{d t}=\frac{B}{2} \frac{d \beta}{d t}+R\{B \beta-\alpha\}\{1-\alpha\}\left\{K_{1}^{\prime}+K_{1}\left(\frac{C_{0}}{E_{0}}+\alpha\right)\right\} \\
& \frac{d \beta}{d t}=\{1-\beta\}\{1-\alpha\}\left\{K_{1}^{\prime}+K_{1}\left(\frac{C_{0}}{E_{0}}+\alpha\right)\right\}
\end{aligned}
$$


$\mathrm{C}_{0}, \mathrm{~A}_{10}$ and $\mathrm{E}_{0}$ are the initial concentrations of catalyst $([\mathrm{OH}])$, primary amine and epoxy groups expressed in mol kg-1 It should be noted that all the concentrations are referred to functional groups, not molecular entities. $R$ is the ratio of rate constants $R=k_{2} / k_{1}=k^{{ }}{ }_{2} / k^{{ }}{ }_{1}$, and its value is assumed to be independent of the reaction path. $\mathrm{K}_{1}=\mathrm{k}_{1} \times\left(\mathrm{E}_{0}\right)^{2}$ and $\mathrm{K}^{\prime}{ }_{1}=\mathrm{k}^{\prime}{ }_{1} \times\left(\mathrm{E}_{0}\right)$, are the global rate constants for the auto-catalyzed and non-catalyzed path respectively. The constant ratio $\mathrm{R}$ can be obtained experimentally following the published method. ${ }^{[8]}$ When the secondary amine variation with reaction time reaches a maximun $\left(\mathrm{d}\left(\mathrm{A}_{2}\right) / \mathrm{dt}=0\right), \mathrm{R}$ is evaluated as the quotient of amine concentrations, with $\mathrm{R}=\mathrm{A}_{1} / \mathrm{A}_{2}$.

Auto-acceleration. At a given conversion, kinetics deviate from the model because of autoacceleration. Our proposal is that, within the scale of reaction times, branching points (tertiary amine nodes) move slower than monomers, forming regions that exclude reactive groups. The experimentally determined reactive mass concentration $C_{i}^{E X P}=n_{i} / m_{T}$ should be substituted by an "effective" concentration, defined in terms not of the total mass but of the accessible mass, $\mathrm{C}_{\mathrm{i}}^{\text {eff }}=\mathrm{n}_{\mathrm{i}} / \mathrm{m}_{\mathrm{acc}}$. The effective mass can be calculated by subtracting from the total mass a fraction of the tertiary amine formed according to equation (3):

$$
\mathrm{C}_{\mathrm{i}}^{\text {eff }}=\frac{\mathrm{n}_{\mathrm{i}}}{\mathrm{m}_{\mathrm{acces}}}=\frac{\mathrm{n}_{\mathrm{i}}}{\left(\mathrm{m}_{\mathrm{T}}-\mathrm{m}_{\mathrm{A} 3}\right)}=\frac{\mathrm{C}_{\mathrm{i}}^{\mathrm{EXP}}}{\left\{1-\frac{\mathrm{n}_{\mathrm{A} 3} \mathrm{M}_{\mathrm{A} 3}}{\mathrm{~m}_{\mathrm{T}}}\right\}}=\frac{\mathrm{C}_{\mathrm{i}}^{\mathrm{EXP}}}{1-\xi \mathrm{A}_{3} \mathrm{M}_{\mathrm{A} 3}}
$$

$A_{3}$ and $M_{A 3}$ are the mass concentration and molar mass of tertiary amine; $f_{a}$ is the autoacceleration factor that should increase with tertiary-amine concentration. The correction factor $\xi$ is necessary to express the fraction of tertiary amine that remains immobile within the reaction time-scale; its value must be constant and comprised between 0 and 1 . If $\xi=1$, all the tertiary amine groups form, within the reaction time-scale, rigid branching points. Introduction of equation (3) into equations (1) and (2) leads to equations (4) and (5):

$$
\begin{aligned}
& \frac{\mathrm{d} \alpha}{\mathrm{dt}}=\frac{\mathrm{B} d \beta}{2} \frac{\mathrm{dt}}{\mathrm{dt}} \mathrm{R}\{\mathrm{B} \beta-\alpha\}\left\{1-\alpha\left\{\mathrm{K}_{1}^{\prime} \times \mathrm{f}_{\mathrm{a}}^{2}+\mathrm{K}_{1} \times \mathrm{f}_{\mathrm{a}}^{3}\left(\frac{\mathrm{C}_{0}}{\mathrm{E}_{0}}+\alpha\right)\right\}\right. \\
& \frac{\mathrm{d} \beta}{\mathrm{dt}}=\{1-\beta\}\{1-\alpha\}\left\{\mathrm{K}_{1}^{\prime} \times \mathrm{f}_{\mathrm{a}}^{2}+\mathrm{K}_{1} \times \mathrm{f}_{\mathrm{a}}^{3}\left(\frac{\mathrm{C}_{0}}{\mathrm{E}_{0}}+\alpha\right)\right\}
\end{aligned}
$$




\section{Experimental}

Reactants. The epoxy resin selected was the diglycidyl ether of bisphenol-A (DGEBA), ex Aldrich, with a molar mass of $348 \mathrm{~g} \mathrm{~mol}^{-1}$. The aliphatic amines, 1,2-ethylendiamine (EDA), 1,5-diaminopentane (DAP), 1-methyl-1,5-diaminopentane (DAMP), 1,2-transcyclohexyldiamine (t-ChDA) and m-xylendiamine (m-XDA) were all supplied by Aldrich with a minimum purity of $98 \%$. Poly(3-aminopropylmethylsiloxane) (PAMS) was synthesized from 3-aminopropylmethyl-diethoxysilane monomer (ABCR) by hydrolysis and a condensation reaction. ${ }^{[10]}$ The liquid oligomer $\left(\mathrm{Tg}=-65^{\circ} \mathrm{C}\right)$ was characterized by SEC, VPO (Knauer) and ${ }^{29} \mathrm{Si}$ NMR spectroscopy (Gemini). The number-average molar mass measured by VPO was $1620 \pm 90 \mathrm{~g} \mathrm{~mol}^{-1}$ and $1570 \mathrm{~g} \mathrm{~mol}^{-1}$ by ${ }^{29} \mathrm{Si}$ NMR. All reactants were degassed and used with no further purification.

Conversion measurements. Stoichiometric DGEBA/amine mixtures were prepared at room temperature and placed in a mould between two glass slides separated by a Teflon sheet. Curing temperatures were selected between 40 and $120{ }^{\circ} \mathrm{C}$. Fourier transform near-infrared spectroscopy (FT-nIR, Perkin Elmer GX2000) was used to obtain concentration data, ${ }^{[1]}$ following the decrease in the area of the oxirane $\left(4530 \mathrm{~cm}^{-1}, \mathrm{~S}_{4530}(\mathrm{t})\right)$ and primary amine bands $\left(4940 \mathrm{~cm}^{-1}, \mathrm{~S}_{4940}(\mathrm{t})\right)$, both normalized to a reference $\mathrm{C}-\mathrm{H}$ band $\left(4623 \mathrm{~cm}^{-1}, \mathrm{~S}_{4530}(\mathrm{t})\right) . \alpha$ and $\beta$ were obtained from the following expressions. Secondary and tertiary amine concentrations were obtained by mass balance:

$$
\begin{array}{ll}
\alpha=1-\frac{\mathrm{S}_{4530}(\mathrm{t}) / \mathrm{S}_{4623}(\mathrm{t})}{\mathrm{S}_{4530}(0) / \mathrm{S}_{4623}(0)} & \beta=1-\frac{\mathrm{S}_{4940}(\mathrm{t}) / \mathrm{S}_{4623}(\mathrm{t})}{\mathrm{S}_{4940}(0) / \mathrm{S}_{4623}(0)} \\
{\left[\mathrm{A}_{2}\right]=\left[\mathrm{E}_{0}\right][\mathrm{B} \beta-\mathrm{e}]} & {\left[\mathrm{A}_{3}\right]=\left[\mathrm{E}_{0}\right]\left[\alpha-\beta \frac{\mathrm{B}}{2}\right]}
\end{array}
$$

Calculation method. From initial FT-IR data, $\alpha, \beta, \mathrm{A}_{1}, \mathrm{~A}_{2}$ and $\mathrm{A}_{3}$ were derived. $\mathrm{R}$ was determined graphically by plotting primary and secondary amine concentration versus time. The best fit of the experimental data to equations (1) and (2) was obtained with a Matlab routine by solving simultaneously both differential equations at low conversions, inside a minimizing loop for obtaining $\mathrm{K}_{1}$ and $\mathrm{K}_{1}$. Using the value of the global kinetics constants, $\mathrm{f}_{\mathrm{a}}$ was calculated for each conversion so as to satisfy equations (4) and (5). A plot of $1 /$ fa versus $A_{3}$ gave $\xi$ from the slope in the linear region. 


\section{Results and Discussion}

The variations of primary, secondary and tertiary amine concentration with reaction time are presented for DGEBA /m-XDA in Figure 1, as an example. A maximum in the secondary amine concentration is clearly seen. All the systems studied gave similar concentration plots in the observed temperature range. From these plots, the constant ratio $\mathrm{R}$ was determined, varying between 0.2 and 0.4 and being independent of temperature.

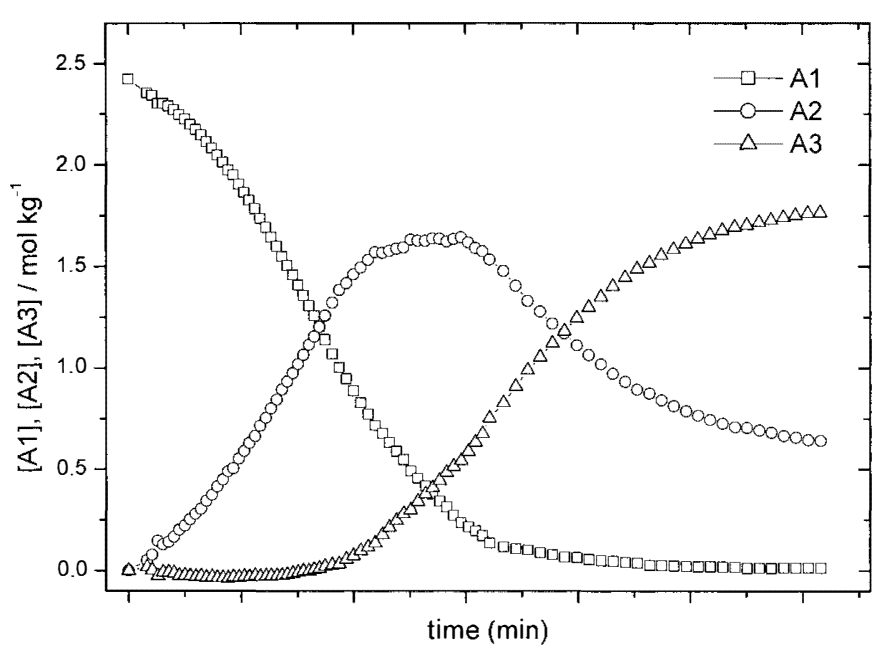

Fig. 1. Concentration of primary (A1), secondary (A2) and tertiary (A3) amine groups versus reaction time for the system $\mathrm{DGEBA} / \mathrm{m}-\mathrm{XDA}$ cured at $80^{\circ} \mathrm{C}$.

Simultaneous fitting to the values of $\alpha$ and $\beta$ with Matlab using equations (1) and (2) gave good fits at low conversions, as can be seen from the trend of the residuals in Figure 2.

The conversion intervals for fitting were selected along with the criterion to minimize errors. The introduction of the primary amine conversion into the fitting equations is relatively unusual in the literature. We have confirmed that sensibly different results are obtained if kinetics parameters are obtained only with epoxy conversion. 

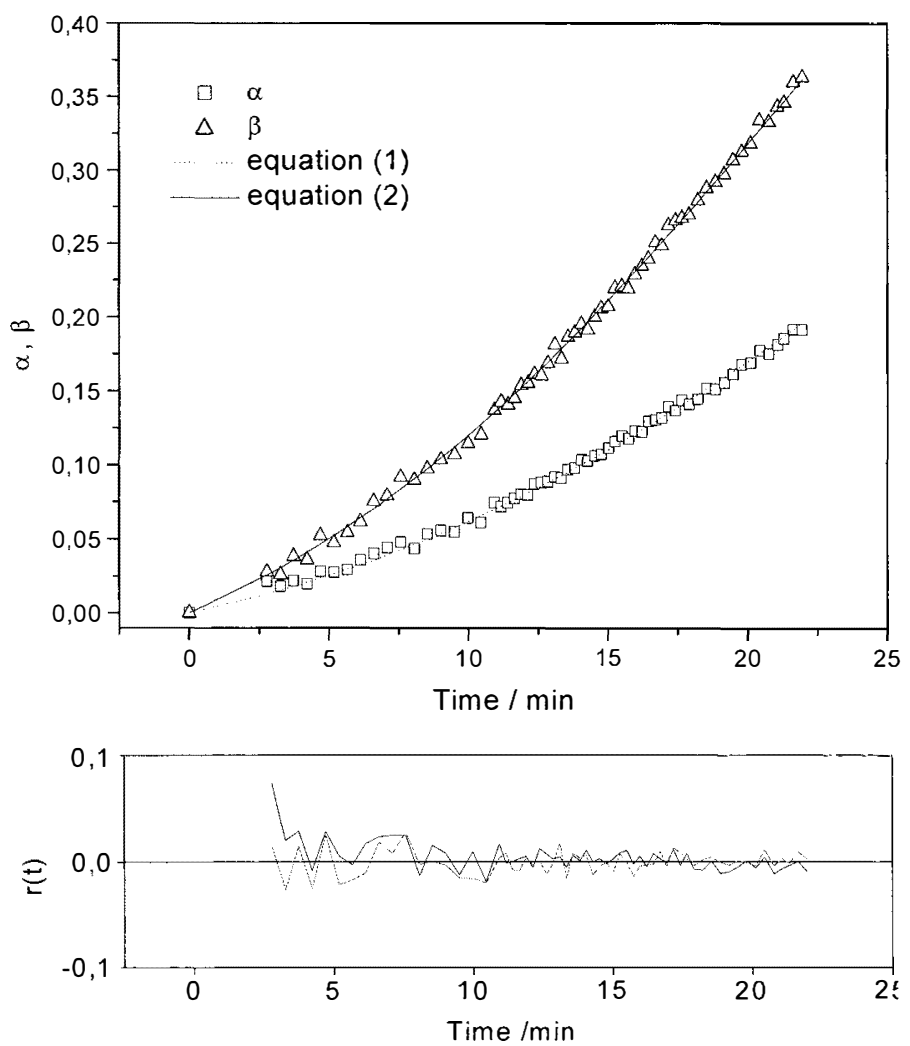

Fig. 2. $\alpha$ and $\beta$ as functions of curing time for DGEBA / m-XDA at $60{ }^{\circ} \mathrm{C}$. Curves: fits to eqs (1) and (2). Below: weighted residuals calculated as

$$
\mathrm{r}\left(\mathrm{t}_{\mathrm{i}}\right)=\frac{\mathrm{O}\left(\mathrm{t}_{\mathrm{i}}\right)-\mathrm{C}\left(\mathrm{t}_{\mathrm{i}}\right)}{\sqrt{\mathrm{O}\left(\mathrm{t}_{\mathrm{i}}\right)}}
$$

were $\mathrm{O}\left(\mathrm{t}_{\mathrm{i}}\right)$ and $\mathrm{C}\left(\mathrm{t}_{\mathrm{i}}\right)$ are the observed and calculated values of $\alpha$ (or $\left.\beta\right)$ respectively.

From Arrhenius plots, the activation energies and pre-exponential factors were obtained for all the DGEBA/amine systems studied. They are presented in Table I. From inspection of the table, most of the systems present, as expected, a high activation energy for the non-catalyzed path. For low molar-mass aliphatic amines as EDA, DAP and DAMP, $E_{\mathrm{a}}$ has the same value for both paths within the experimental error. The catalytic effect in these systems is not clear, probably due to the very fast reaction rates at the curing temperatures selected. 
Table 1. Activation energies, pre-exponential factors (A) and correction factor, $\xi$.

\begin{tabular}{c|ccccc}
\hline Amine & $\mathrm{E}_{\mathrm{a}}\left(\mathrm{K}_{1}\right)$ & $\mathrm{A}\left(\mathrm{K}_{1}\right)$ & $\mathrm{E}_{\mathrm{a}}\left(\mathrm{K}_{1}^{\prime}\right)$ & $\mathrm{A}\left(\mathrm{K}_{1}^{\prime}\right)$ & $\xi$ \\
\hline & $\mathrm{kcal} \mathrm{mol}$ & & $\mathrm{kcal} \mathrm{mol}^{-1}$ & & \\
\hline PAMS & $12.0 \pm 0.7$ & $1.7 \times 10^{7}$ & $16.3 \pm 0.4$ & $9.9 \times 10^{8}$ & $0.42 \pm 0.04$ \\
EDA & $13.1 \pm 0.3$ & $8.5 \times 10^{7}$ & $12.7 \pm 0.1$ & $3.6 \times 10^{6}$ & $0.44 \pm 0.02$ \\
m-XDA & $11.5 \pm 0.7$ & $5.9 \times 10^{6}$ & $14.1 \pm 1.4$ & $8.0 \times 10^{6}$ & $0.63 \pm 0.04$ \\
DAP & $11.9 \pm 1.8$ & $1.4 \times 10^{7}$ & $11.6 \pm 4.1$ & $5.6 \times 10^{5}$ & $0.45 \pm 0.04$ \\
DAMP & $13.0 \pm 1.0$ & $4.1 \times 10^{7}$ & $11.5 \pm 0.8$ & $5.6 \times 10^{5}$ & $0.48 \pm 0.04$ \\
$\mathrm{t}$-ChDA & $9.6 \pm 2.2$ & $2.9 \times 10^{5}$ & $11.9 \pm 3.6$ & $2.4 \times 10^{5}$ & $0.44 \pm 0.02$ \\
\hline
\end{tabular}

The use of equations (1) and (2) at high curing times gives systematic deviations to lower conversions than those observed experimentally, as shown in Fig. 3, except for the last stages of the reactions, when the systems vitrify.

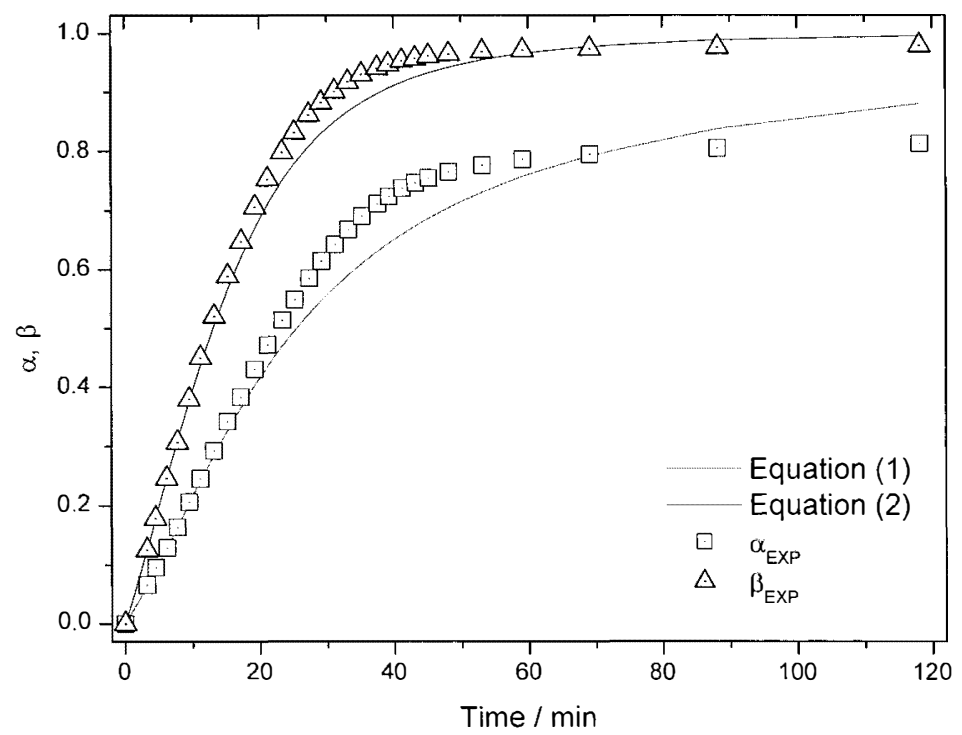

Fig. 3. Comparison between predicted conversions using equation (1) and (2) and experimental data, for the system DGEBA/PAMS, cured at $60^{\circ} \mathrm{C}$.

With the known kinetics constants, experimental data were fitted to equations (4) and (5) and the fitting factor $f_{a}$ was obtained for each conversion. Using equation (3), the inverse, $1 / f_{a}$, was 
plotted against the tertiary amine concentration and a linear fit was observed, as shown in Figure 4. Good linear fits were obtained for all the systems over a wide range of $\mathrm{A}_{3}$ concentrations. This fact, in principle, validates our a priøri supposition concerning the relation between auto-acceleration and tertiary amine concentration. Only when the system reaches vitrification does $\mathrm{f}_{\mathrm{a}}$ apparently decrease because the reaction becomes diffusion controlled.

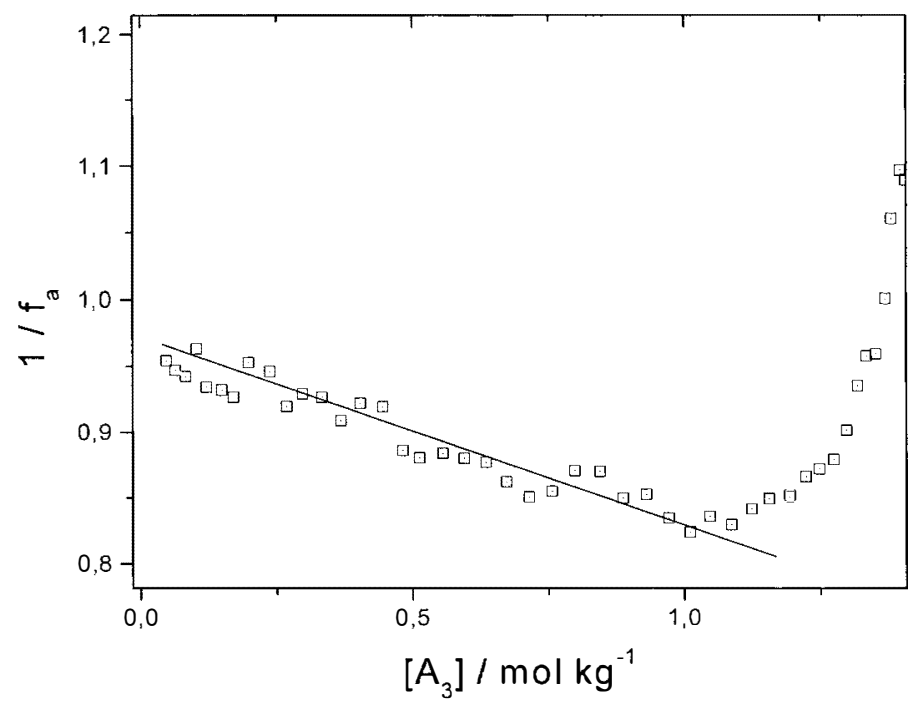

Fig. 4. Representation of the inverse of the fitting factor $\left(\mathrm{f}_{\mathrm{a}}\right)$ versus tertiary amine concentration for the system DGEBA/EDA cured at $50^{\circ} \mathrm{C}$.

Assuming the mass of the tertiary amine is the sum of the masses of the branched segments, a single parameter $\xi$ is obtained from the slope and is presented in table 1 for each epoxy/amine system. This parameter estimates the mass fraction of tertiary amine species that remains immobile within the reaction time scale and it should be expected that the more rigid systems will lead to more rigid branches and, therefore, $\xi$ should be higher. The highest value of $\xi$ was obtained for the most rigid amine, $\mathrm{m}-\mathrm{XDA}$, and the lowest value of $\xi$ was obtained for the very flexible siloxane-chain PAMS. Small differences amongst the simple aliphatic amines were obtained. From the values of $\xi$, a rigidity scale can be established as follows PAMS $<$ EDA $\approx$ $\mathrm{ChDA}<\mathrm{DAP}<\mathrm{DAMP}<<\mathrm{m}-\mathrm{XDA}$. The exception seems to be $\mathrm{t}-\mathrm{ChDA}$, for which a more rigid branching point should be expected. 


\section{Conclusions}

The curing kinetics of DGEBA with six different aliphatic diamines has been analysed in terms of the 4EQ kinetic model (Horie model) over a wide temperature range. The auto-acceleration effect was observed in all cases and it has been interpreted to be a consequence of the formation of immobile species that can be associated with tertiary amines.

A model for auto-acceleration has been proposed in terms of a single parameter, $\xi$, that estimates the mass fraction of tertiary amine species that excludes reactive groups on the reaction time-scale. This parameter seems to be independent of temperature within the error of its determination, at least over the temperature range studied. It seems also that for the rigid amine system (m-XDA) the parameter is highest and for the most flexible system (PAMS) it has the lowest value, suggesting that the initial hypothesis of the model is correct.

\section{Acknowledgements}

Authors gratefully acknowledge to (AM (Pricit) and to project Epoxsil (MAT2000-0391-P4-02) for financial support.

[1] K. Horie, H. Hiura, M. Sawada, I. Mitta. H. Kambe, J. Polym. Sci. A-I 1970, 8, 1357

[2] M. R. Kamal, Polym. Eng. Sci. 1974, 14, 231

[3] M. E. Ryan, A. Dutta, Polymer 1979. 20.73.

[4] C C. Riccardi, H. E. Addabo. J. J. Williams, J. Appl. Polvm. Sci. 1984. 29. 2481.

[5] K. C Cole, J. J. Hecker, D. Noel, Macromolecules 1991, 24, 2098

[6] S. Vyazovkin, N. Sbirrazuoli, Macromolecules 1996, 29, 1867

[7] S. L. Simon. G. 13. Mckenna, O. Sindt, J. Appl. Polym. Sc l. 2000 -, 495

[8] S. Paz-Abuín, A. I.opez-Quintela, M. I arela. M P. Pellín. P. Prendes, Polımer 1997. 38. 3117

[9] S. Paz-Abuín. A. Lopez-Quintela, M. P. Pellín. M. Varela. P Prendes, J Polym A-Polm ('hem. 1998. $36,1001$.

[10] J. C Cabanelas. B. Serrano. J. Gonzalez-Benitc. J. Braıo. J. Baselga, Macromol Rapid C'omm 2001, 22. 694.

[11] G. A. Gieorge, P. C. Clarke. N. S Jhon. G Friend. J. Appl. Polym Scr. 1991, 42, 6.43. 